\title{
INVESTIGATION OF TILLAGE DEPTH OF BLACK FALLOW IMPACT UPON MOISTURE EVAPORATION INTENSITY
}

\author{
Valerii Adamchuk ${ }^{1}$, Volodymyr Bulgakov ${ }^{2}$, Volodymyr Nadykto ${ }^{3}$, Semjons Ivanovs ${ }^{4}$ \\ ${ }^{1}$ National Scientific Centre "Institute for Agricultural Engineering and \\ Electrification" of Ukraine, Ukraine; ${ }^{2}$ National University of Life and Environmental Sciences of \\ Ukraine, Ukraine; ${ }^{3}$ Tavria State Agrotechnological University, Ukraine; \\ ${ }^{4}$ Latvia University of Life Sciences and Technologies, Latvia \\ semjons@apollo.lv
}

\begin{abstract}
Despite the current trends to reduce the number of operations, ploughing remains the most important technological operation of tillage. In the regions with insufficient moisture, preservation of moisture in the arable layer of the soil is the most important task, which determines its efficient fertility, affecting the processes that take place in it and ensuring the technological properties during mechanical tillage. To refine the technology and technical means for the implementation of this operation is an urgent scientific and practical task. One of the technological ways how to save and even accumulate the insufficient soil moisture is the black fallow. Yet the achievement of this result is possible only by proper tillage of the fallow. First of all, this concerns the depth of its loosening. To solve this problem under the conditions of an arid climate, particularly under the soil and weather conditions of the south of Ukraine, we studied theoretically and experimentally the heat balance of the treated soil layer of the black fallow. As a result of this study, an equation was obtained for analytical determination of the evaporation rate of the soil moisture from this layer. It has been established by the conducted studies that moisture evaporation on the fallow increases rapidly, when the tillage depth is increased up to $4 \mathrm{~cm}$. The subsequent increase in the parameter causes a further increase in the moisture loss; however, the intensity of this process is significantly reduced. The obtained results of the research made it possible to select and optimise the necessary form of the working tools of the soil tillage machine to be used for tillage of the black fallow.
\end{abstract}

Keywords: moisture, soil, evaporation, black fallow, intensity.

\section{Introduction}

Despite the active introduction of new technologies, mechanical tillage still occupies an important place in the system of creating favorable conditions for the development of crops [1-3]. In many regions, especially in arid steppe zones, a system of so-called black fallow steam is used, the processing of which begins in the summer-autumn period. A fallow is a crop rotation field on which crops have not been cultivated for a certain period. These fields are carefully cultivated, fertilized and kept clean from weeds. In the regions with insufficient moisture, preservation of moisture in the arable layer of the soil is the most important task, which determines its efficient fertility, affecting the processes that take place in it and ensuring the technological properties during mechanical tillage. To refine the technology and technical means for the implementation of this operation is an urgent scientific and practical task.

It has been established by long-term investigations that in most cases of care for fallow more than $75 \%$ of the precipitated moisture cannot be preserved [4-5]. In the same work it is noted that even to retain $25 \%$ of the precipitated moisture on the fallow, considerable effort is required. This particularly applies to the so-called black fallow.

Very often the use of fallow is determined by the pricing policy for grain crops [6-8]. Under dry soil conditions in the USA, not more than $30 \%$ of precipitation could be retained in the soil [9]. Evaporation accounts for most of the precipitation lost. The same article states that in a fallow period of approximately 20 months, approximately $3 / 4$ of the precipitation will be irretrievably lost. If only one tenth of the lost water $(4.5 \mathrm{~mm})$ could be saved in addition to the one that is usually saved, wheat production in the marginal areas would increase by about $25 \%$.

Also, on the basis of soil studies in its various states, it was found that a decrease in moisture evaporation is associated with the problem of its separating in the soil from the heat sources. Concentration of the water vapour in the soil air decreases rapidly with decreasing soil temperature. This concentration should be lower than the concentration of the water vapour above the soil surface.

The second stage of moisture evaporation begins, when the rate of the upward movement of the soil moisture becomes lower than the rate of its evaporation. In this case, the drying soil is a screen 
that separates the lower soil layer from the warm air. However, the dry soil limits the upward movement of the liquid moisture, but not its vapour. One of the ways how to reduce evaporation of moisture from the soil is to increase the pores of the soil on its surface (i.e. actually disrupt the soil capillarity). Loosened soil dissipates more solar (thermal) energy. Investigations have also been conducted to determine the amount of moisture evaporated from the soil when it is loosened to a depth of 2.5 and $7.5 \mathrm{~cm}$ [9-11].

\section{Materials and methods}

Experimental research was carried out to study the effect of the cultivation depth of the black fallow on the rate of the moisture evaporation, as well as to verify the adequacy of the obtained analytical expressions. So, under real field conditions, experimental investigations were carried out, for which a machine-and-tractor aggregate was composed of an aggregating tractor and a harrow (Fig. 1). In Fig. 2 there is shown this harrow with advanced teeth (flat-cutting working elements at the ends of the tines, a working width $80 \mathrm{~mm}$ ) intended for treating steam fields under arid conditions.

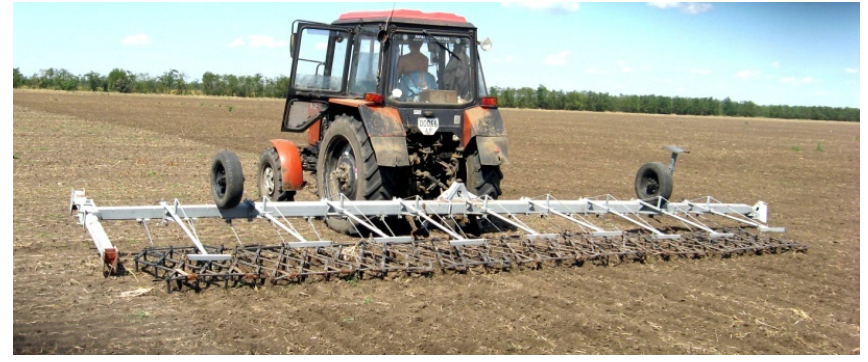

Fig.1. Tillage aggregate for processing fallow during the experimental field investigations

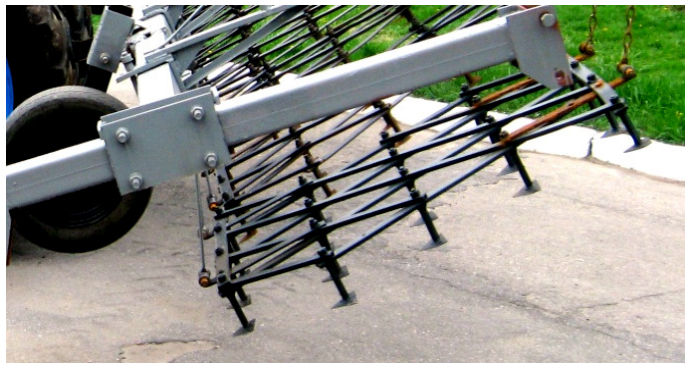

Fig. 2. Working bodies of the harrow for processing fallow, equipped with flat cutting teeth

To measure the soil moisture, we used the MG-44 electronic device with an accuracy of $\pm 1 \%$ (Fig. 3). Measuring the soil density was carried out by our device and method. The number of measurements of each of the parameters $W$ and $\rho_{q}$ was 50 .

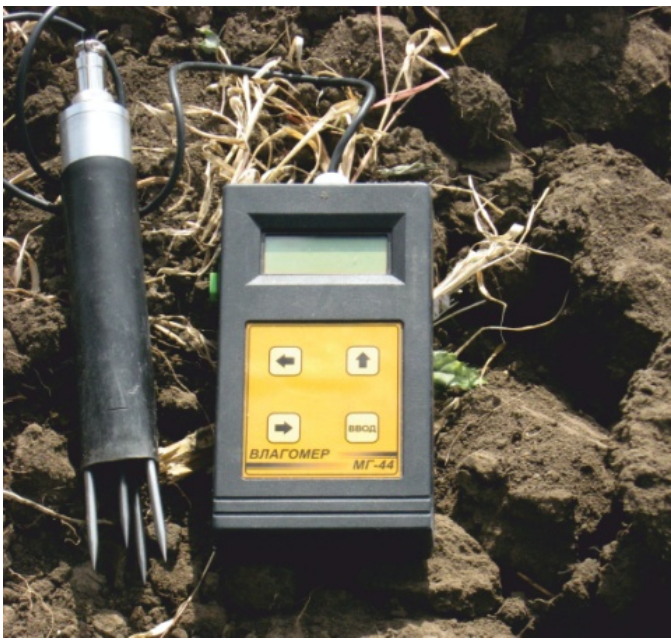

Fig.3. Device for measuring soil

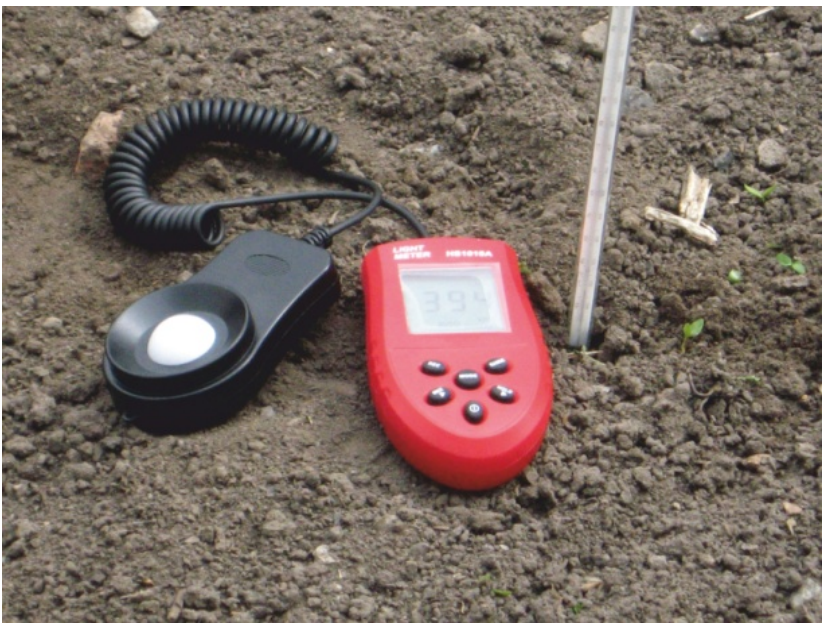

Fig.4. Instruments for measuring illumination and soil temperature

The field illumination was recorded with an HS 1010A light meter (Fig. 4) with a measurement accuracy of \pm 1 lux. The temperature of the surface air and soil was measured with mercury thermometers (Fig. 4) with an accuracy of $\pm 0.1^{\circ} \mathrm{C}$. The measurement quantity of each parameter was not less than 30 .

The heat balance equation for the mulching soil layer, which can be expressed in the following way [11]: 


$$
E_{s}-E_{r}-E_{v}-E_{a}-E_{q}=0,
$$

where $E_{s}-$ solar energy, $\mathrm{W} \cdot \mathrm{m}^{-2}$;

$E_{r}-$ amount of solar energy reflected from the soil, $\mathrm{W} \cdot \mathrm{m}^{-2}$;

$E_{v}-$ energy spent on evaporation of moisture from the soil, $\mathrm{W} \cdot \mathrm{m}^{-2}$;

$E_{a}$ - energy spent on heating the surface air, $\mathrm{W} \cdot \mathrm{m}^{-2}$;

$E_{q}$ - energy spent on heating the soil, $\mathrm{W} \cdot \mathrm{m}^{-2}$.

From expression (1) we determine the energy, spent on evaporation of moisture:

$$
E_{v}=E_{s}-E_{r}-E_{a}-E_{q} .
$$

The energy of solar radiation is determined from the following known dependence [8]:

$$
E_{s}=L_{s} \cdot K_{t}^{-1},
$$

where $L_{s}$ - illumination of the surface of the mulching soil layer, $\mathrm{lm} \cdot \mathrm{m}^{-2}$;

$K_{t}$ - conversion factor in the transition from the light to energy values, $1 \mathrm{~m} \cdot \mathrm{W}^{-1}$.

In this case, this coefficient should be used to evaluate the light output of the sun, which is approximately $93 \mathrm{~lm} \cdot \mathrm{W}^{-1}$. The degree of the reflected energy of solar radiation from the soil, as is known, is directly proportional to its albedo $A_{q}$. In this case, we will have such a value of the amount of solar energy, reflected from the soil $E_{r}$ :

$$
E_{r}=A_{q} \cdot E_{s}=A_{q} \cdot \frac{L_{s}}{K_{t}} .
$$

It should be noted that, according to the results of many years' research, the average value of the albedo $A_{q}$ of freshly loosened humus soil for the steppe, often arid conditions, is 0.08 . The amount of the energy spent on turbulent heat exchange with surface air can be determined from the following relationship:

$$
E_{a}=\frac{K_{a}}{h_{a}} \cdot T_{a q},
$$

where $K_{a}$ - coefficient of thermal conductivity of air (at the temperature change in the range of $10 \ldots 50$ degrees $K_{a}$ varies relatively little and under arid conditions it is, on the average, equal to $0.0267 \mathrm{~W} \cdot \mathrm{m} \cdot$ deqrees $^{-1}$;

$h_{a}$ - height of the estimated surface air column, m;

$T_{a q}$ - temperature difference between the surface air layer and the upper soil layer, degrees.

By analogy with expression (5), the thermal energy $E_{q}$ used to heat the soil will be equal [8]:

$$
E_{d}=\frac{K_{q}}{h_{q}} \cdot T_{q q}
$$

where $K_{q}$ - thermal conductivity coefficient of the upper mulching soil layer, W.(m.deqrees) ${ }^{-1}$;

$h_{q}$ - depth of the mulching layer of the soil, m;

$T_{q q}$ - temperature difference between the mulching and underlying soil layers, degrees.

Further we determine the loss of moisture in the soil during its evaporation. For this we will use the main provisions presented in the work [8]. It is noted there that, using the energy of moisture evaporation $E_{f}$ from the soil of the field with an area $S_{f}$, it is possible to determine the intensity of its loss $I_{b}$ over time, $\left(\mathrm{mm} \cdot \mathrm{h}^{-1}\right)$. Thus, we have:

$$
I_{b}=\frac{E_{f}}{L_{w} \cdot S_{f} \cdot \rho_{w}}
$$

where $L_{w}-$ specific heat of vaporization of water $-632.2 \mathrm{~W} \cdot \mathrm{h} \cdot \mathrm{kg}^{-1}$; 


$$
\begin{aligned}
& S_{f}-\text { area of the field, } \mathrm{m}^{2} ; \\
& \rho-\text { density of water, } 10^{3} \mathrm{~kg} \cdot \mathrm{m}^{-3} .
\end{aligned}
$$

Since the energy of moisture evaporation $E_{f}$ from the entire field $S_{f}$ may be equal to:

$$
E_{f}=E_{v} \cdot S_{f},
$$

then the rate of the moisture loss during evaporation will be equal to:

$$
I_{b}=\frac{E_{v} \cdot S_{f}}{L_{w} \cdot S_{f} \cdot \rho_{w}}=\frac{E_{v}}{L_{w} \cdot \rho_{w}} .
$$

Having finally expressed the amount of the energy spent on the evaporation of moisture from the soil $E_{v}$ from expression (2) through the components contained in expressions (3) - (6) and substituting the resulting equation in formula (9), after some transformations we finally obtain the moisture loss intensity $I_{b}$ in such a form:

$$
I_{b}=\frac{\left(1-A_{q}\right) \cdot \frac{L_{s}}{K_{t}}-\frac{K_{a}}{h_{a}} \cdot T_{a q}-\frac{K_{q}}{h_{q}} \cdot T_{q q}}{L_{w} \cdot \rho_{w}},
$$

Thus, a final analytical expression is obtained that allows one to determine the intensity of the moisture loss during evaporation in any state of the soil. When specifying the values included in it, there is a possibility to use a PC to simulate the dependence of the rate of moisture loss $I_{b}$ on the type and depth of soil cultivation, illumination, and other parameters.

To check the adequacy of equation (8), the values of moisture evaporation intensity, calculated from it, were compared with the experimental data, determined using formula (10).

The methodology for conducting experimental studies provided for:

- before the passage of the experimental tillage aggregate, the following parameters were measured: the moisture $(W)$ and density $\left(\rho_{q}\right)$ of a layer of soil, 0 to $15 \mathrm{~cm}$ thick;

- after the aggregate had passed, there were measured: the illumination of the treated field $\left(L_{s}\right)$; soil loosening depth $\left(h_{q}\right)$; surface air temperature; temperature of the loosened soil at the surface and at the depth of processing, and the moisture reserve $\left(M R_{\mathrm{o}}, \mathrm{mm}\right)$ in the loosened soil. To determine the moisture reserve, the following expression was used:

$$
M R_{\mathrm{o}}=0.1 \cdot W \cdot \rho_{q} \cdot h_{q} .
$$

After a temporary pause, 1 hour long, the parameters $W$ and $\rho_{q}$ were measured again, and the moisture supply value $M R_{1}$ was recalculated. The difference between the two measurements was the moisture evaporation rate $I_{b}\left(\mathrm{~mm} \cdot \mathrm{h}^{-1}\right)$ from the layer of soil $h_{q}(\mathrm{~m})$, obtained experimentally:

$$
I_{b}=M R_{\mathrm{o}}-M R_{1} .
$$

To ensure the reliability of comparison of the calculated and the experimental data, the arrays of the measured parameters of the moisture $(W)$, density $\left(\rho_{q}\right)$, illumination $\left(L_{s}\right)$, processing depth $\left(h_{q}\right)$ and the soil temperature, as well as the air temperature were checked to establish the presence of dubious criteria according to J. Irwin [12]. The calculated values of the J. Irwin criterion were compared with tabular values, adopted for the statistical level of significance 0.05 . In case the condition (13) is violated, the dubious variant of the measured parameter was excluded from the data array.

\section{Results and discussion}

The experimental field studies of the soil cultivation aggregate on a fallow were carried out at two levels of its illumination: 48000 lux and 65000 lux. In the first case, the temperature difference between the surface air layer and the upper soil layer was $8^{\circ} \mathrm{C}$, and between the mulching and the underlying soil layers $-4^{\circ} \mathrm{C}$.

At the second level of field illumination, these parameters were as follows: $T_{a q}=10.0^{\circ} \mathrm{C}$ and $T_{a q}=4.5^{\circ} \mathrm{C}$. Using the analytically obtained expression (10), with the help of a PC, a calculation was made and graphical dependences of the moisture evaporation rate $I_{b}$ from the soil upon the depth of its 
treatment at illumination of 48000 and 65000 lux were constructed (Fig. 5 and Fig. 6). Substituting the data obtained experimentally into expression (12), the points of the experimental data are plotted on these graphs. A comparison of the experimental and calculated data indicates their satisfactory proximity at both levels of soil illumination.

The statistical processing revealed the acceptable agreement between the theoretical (calculated) and the experimental research data. The calculated data values practically do not go beyond the limits of the confidence intervals of the experimental values of the measured parameters, presented in Fig. 5 and 6.
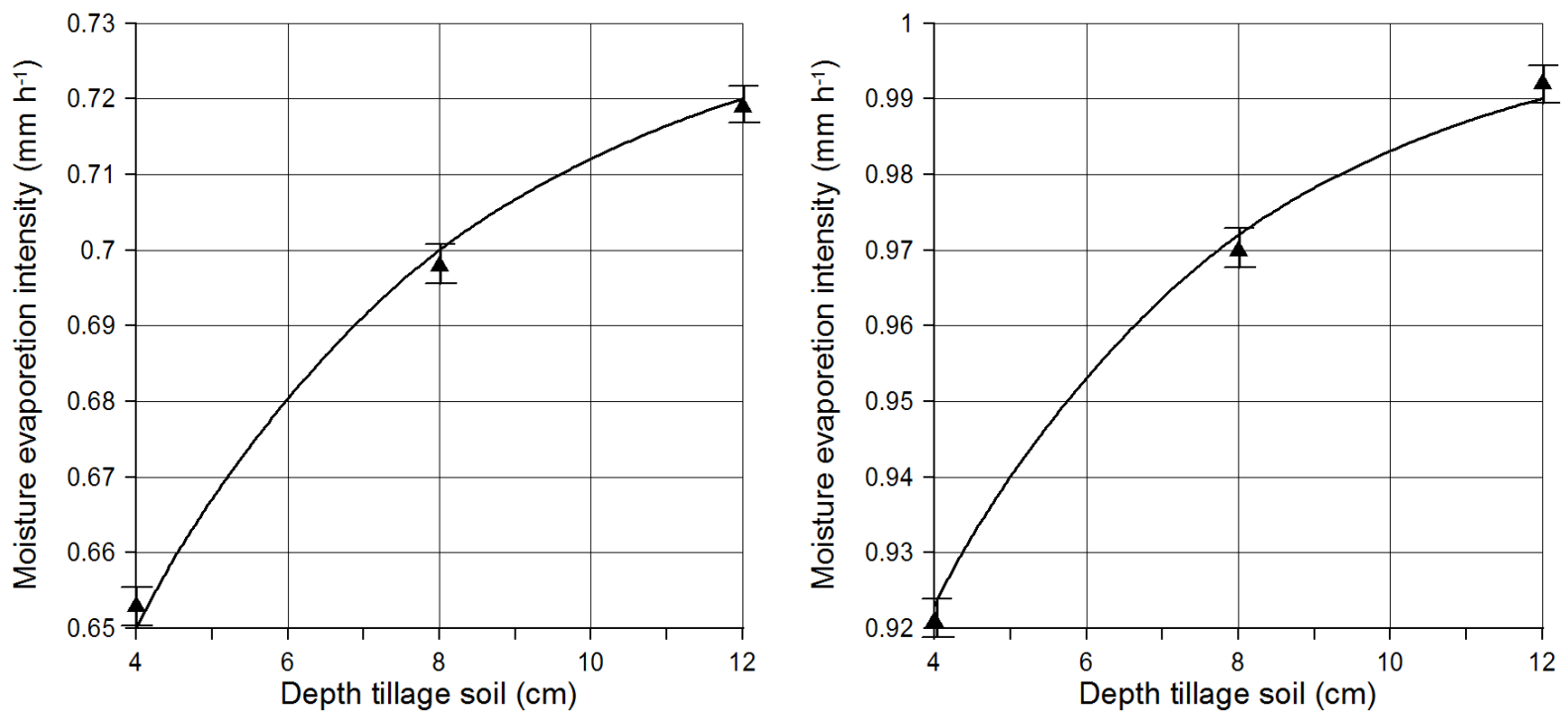

Fig. 5. Dependence of the moisture evaporation rate from the soil on the depth of its processing at illumination of 48,000 lux:

Fig. 6. Dependence of the moisture evaporation rate from the soil on the depth of its processing at illumination of 65,000 lux:

— theoretical curve; $\boldsymbol{\Delta}$ experimental poins

— theoretical curve; $\boldsymbol{\Delta}$ experimental points

This coincidence of theoretical and field data confirms the adequacy of equation (10). And this gives the right to use it for further theoretical research, the results of which can be considered reliable.

In general, the calculations of expression (10), carried out on the PC, show that the rate of evaporation of moisture from the soil is constantly increasing with increasing the depth of processing (Fig. 7). However, this is clearly not uniform. In principle, the process under consideration can be divided into two zones. One of them is characterized by intensive growth of the function $I_{b}$, but the other - by a slower one.

We have developed a mathematical method for determining the separation point of such zones. A graphical interpretation of this method is as follows. It is necessary to connect the extreme points of the curve under study with each other by a straight line. Then this line should be moved parallel to itself until the moment when it becomes tangent to the analysed curve (Fig. 8). The point of contact of these lines will be the one that divides the process considered into the two zones mentioned above. In our case this is point $C$, shown in the graph of Fig. 8. Its location on this graph allows a conclusion that with an increase in the depth of loosening of the soil to about $4 \mathrm{~cm}$, evaporation of moisture occurs intensively. With a further increase in the parameter $h_{q}$, this process tends to slow down.

We also established a new result in computer simulation, which was obtained by studying the dependence (10) in the form:

$$
I_{b}=f\left(T_{a q} ; T_{q q}\right) .
$$

When the difference in these temperatures changes from $0{ }^{\circ} \mathrm{C}$ to $20^{\circ} \mathrm{C}$, the rate of moisture evaporation from a soil layer, $4 \mathrm{~cm}$ thick, decreases linearly (Fig. 9). Besides, at the point where the condition $T_{a q}=T_{q q}$ is satisfied, the value of the quantity $I_{b}$ is the same for both processes: 1) $I_{b}=f\left(T_{a q}\right)$; 2) $I_{b}=f\left(T_{q q}\right)$. 


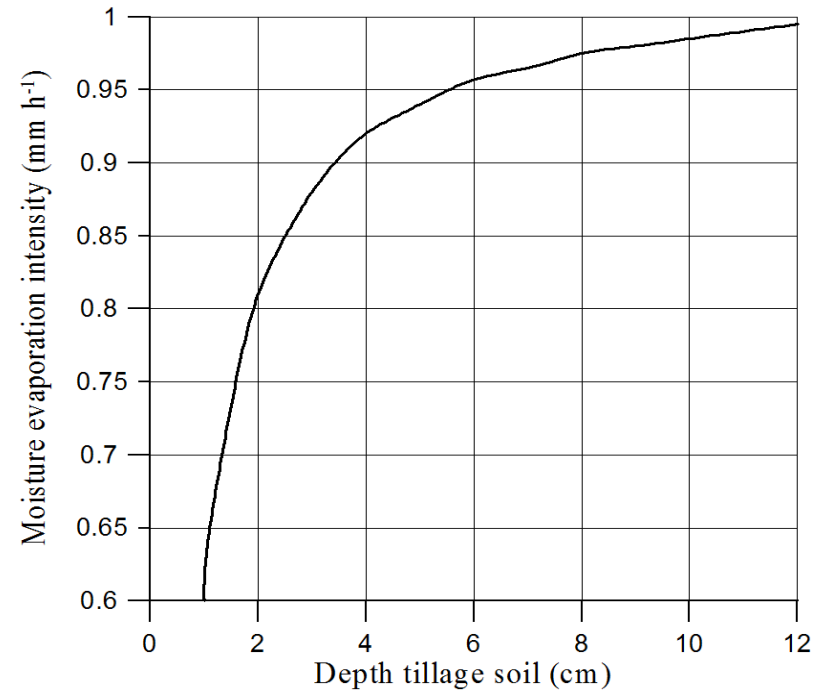

Fig. 7. Dependence of the moisture evaporation rate on the tillage depth

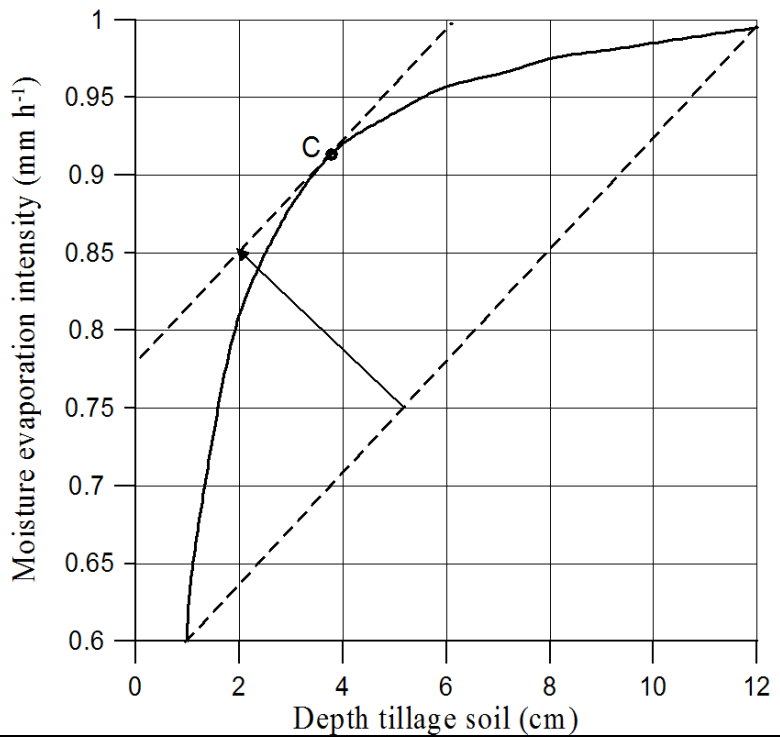

Fig. 8. Methodology of determining the location of point $(\mathbf{C})$ dividing the moisture evaporation rate into two zones

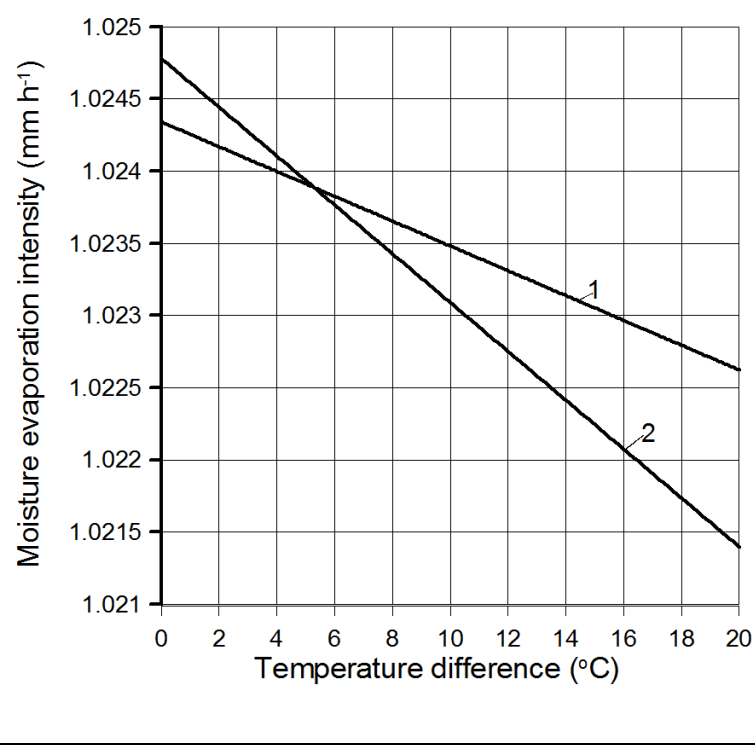

Fig. 9. Dependence of the moisture evaporation rate from the soil upon the temperature difference of the layers at

$$
\boldsymbol{h}_{q}=\mathbf{c m}: 1-T_{a q} ; 2-T_{a q}
$$

It should also be noted that we established, according to the results of the study, such regularity (see. Fig. 9). If in the range of temperature difference $0-5^{\circ} \mathrm{C}$ the parameter $T_{a q}$ determines a higher rate of moisture evaporation from the soil, then in the range of temperature difference $5-20{ }^{\circ} \mathrm{C}$, on the contrary, the parameter $T_{a q}$. At the moment the nature of these regularities requires a more thorough study.

Regarding the nature of the process depicted in the graphs of Fig. 7, its analysis allows us to draw the following important conclusion. To retain moisture on the fallow, it should be treated with such tillage machines, the working bodies of which are able to work at a depth of 4-6 cm. But at the same time, they should only destroy soil capillaries without carrying soil to the day surface of the field. That is, shallow $(4-6 \mathrm{~cm})$ loosening of the soil should be carried out without mixing it.

\section{Conclusions}

1. Theoretically and experimentally the heat balance of the treated soil layer of the fallow is investigated. As a result, we obtained an equation for the analytical determination of the intensity 
of soil moisture evaporation by this layer, which determines the value of the indicator $I_{b}$, includes the depth of loosening the fallow.

2. It was established that, in order to retain moisture in the fallow, it should be treated with such tillage machines, the working bodies of which are able to work at a depth of 4-6 cm. But, at the same time, they should only destroy soil capillaries without carrying soil to the day surface of the field. That is, shallow $(4-6 \mathrm{~cm})$ loosening of the soil should be carried out without mixing it.

3. The results of the study allowed us to select and optimise the necessary form of the working bodies of the tillage machine, which must be used to process the fallow black steam.

\section{References}

[1] Rucins A., Vilde A. Modelling forces acting on the plough body. Simulation in Wider Europe 19th European Conference on. Modelling and Simulation, ECMS 2005, 2005, pp. 425-430.

[2] Barwicki J., Gach St., Ivanovs S. Proper utilization of soil structure for crops today and conservation for future generations. Engineering for Rural Development, proceedings, Vol. 11, 2012, pp. 10-15.

[3] Nadykto V., Velichko I. Curve's optimum point definition and method of its determination. Tech. Technol. AIC 2, 2014, pp. 16-18.

[4] Mielke L.N., Wilhelm W.W., Richards K.A., Fenster, C.R., 1984. Soil physical characteristics of reduced tillage in a wheat-fallow system. Trans. Am. Soc. Agric. Eng. 27, pp. 1724-1728.

[5] Kijowska-Strugała M., Kiszka K. Assessment of the splash on the foothill slope (flysch carpathians, Bystrzanka catchment). Annales Universitatis Mariae Curie-Sklodowska, Sectio B, Vol.69, Issue 2, 2014, pp. 79-95.

[6] Smith E.C., Young D.L. Requiem for summer fallow. CHOICES 24-25, 2000.

[7] Lisetskii F.N., Marinina O.A., Jakuschenko D.G. A new approach to dating the fallow lands in old-cultivated areas of the steppe zone. Research Journal of Pharmaceutical, Biological and Chemical Sciences, Vol. 5, Issue 6, 2014, pp. 1325-1335.

[8] Savel'ev Y.A., Dobrynin Y.M., Ishkin P.A. Theoretical study of soil water balance and process of soil moisture evaporation. Agric. Mach. Technol. 1, 2017, pp. 23-28.

[9] Willis W.O., Bond J.J. Soil Water Evaporation: Reduction by Simulated Tillage. Soil Sci. Soc. Am. J. Abstr. 35, 1971, pp. 526-529.

[10] Masse T.W., Gary J.W., Plains G., Desert A. Potencial for reducing evoporation during summer fallow. Soil Water Conserv., 33, 1978, pp. 126-129.

[11] Vasilyeva N.A., Abiven S., Hilf M., Rizhkov O.V., Schmidt, M.W. Pyrogenic carbon quantity and quality unchanged after 55 years of organic matter depletion in a Chernozem. Soil Biology and Biochemistry. Vol. 43, Issue 9, 2011, pp. 1985-1988.

[12] Agapov I., Nazarov S.A. Comparison of the Griffith and Irwin Criteria for a Crack Asymmetrically Propagating in the Plane. Materials Science, 36 (4), 2000, pp. 561-569. 